\title{
Dermatomiyozit ve malignite birlikteliği: bir olgu örneği
}

\author{
Malignancy in dermatomyositis: a case report \\ Göksel Tanıgör ${ }^{1}$ Hayriye Koçanaoğulları ${ }^{2}$ Figen Yargucu Zihni ${ }^{2}(\mathbb{C}$ \\ ${ }^{1}$ Ege Üniversitesi Tıp Fakültesi, Fiziksel Tıp ve Rehabilitasyon Anabilim Dalı \\ ${ }^{2}$ Ege Üniversitesi Tıp Fakültesi, İç Hastalıkları Anabilim Dalı, Romatoloji Bilim Dalı
}

Gonca Karabulut ${ }^{2}$

\section{Öz}

Dermatomiyozit, hem kas, hem de derinin tutulduğu bir sistemik otoimmün hastalıktır. Hastaların önemli bir kısmında altta bir malignite varlığı tespit edilebilmektedir. Birliktelik genellikle solid organ tümörleri olmakla beraber birçok malign neoplazi ile ilişkili olabilir. Bu nedenle hastalarda sadece hastalık yönetiminin gerçekleştirilmesi değil, sistemik açıdan da detaylı bir şekilde taranması ve gelecekte de bu açıdan izlenmesi önemlidir. Sunulacak olgu bahsettiğimiz birlikteliğe bir örnek teşkil etmektedir.

Anahtar Sözcükler: Dermatomiyozit, inflamatuvar kas hastalığı, kanser, neoplazi, komorbidite.

\section{Abstract}

Dermatomyositis is a systemic autoimmune disease involving both muscle and skin. The presence of a malignancy in a portion of the patients can be detected. The association is usually associated with solid organ tumors but may also be associated with many malignant neoplasms. Thus, it is important not only to carry out disease management in patients, but also to systematically examine them in detail and monitor them in the future. The case to be presented is an example of the relationship that has been mentioned.

Keywords: Dermatomyositis, inflammatory muscle disease, cancer, neoplasia, comorbidity.

\section{Giriş}

Dermatomiyozit, kas ve derinin ön planda tutulumu ile seyreden sistemik ve otoimmün bir hastalıktır. Hastalığın önemli bir özelliği de maligniteler ile birlikte seyredebilmesidir. Yapılan çalışmalarda \%7 ile \%30 arasında birliktelik gösterilmiştir (1-3). Sunumda bu özellikleri gösteren bir olguyu tartışacağız.

\section{Olgu Sunumu}

Otuz sekiz yaşında, bilinen bir kronik hastalığı olmayan kadın hasta, kliniğimize ciltte döküntü ve kas güçsüzlüğü şikâyeti ile başvurmuştur. Başvurudan iki ay önce el dorsumunda plaklar ve eritemli papüller, ardından bilateral alt ekstremitelerde, gövde ve yüzde benzer lezyonlar tariflemiştir. Deri lezyonlarından bir ay sonra kas kuvvetinde azalma tarifleyen hasta dış merkezde yatarak tetkik edilen hastada Kreatin kinaz (CK) değeri 12400 saptanmış. Dermatomiyozit ön tanısı ile tetkik edilmiş olan hastada malignite açısından batın ultrasonografisi (USG), yüksek çözünürlüklü bilgisayarlı tomografi (HRCT) ve meme USG gerçekleştirilmiş, hepatosteatoz ve memede inflamasyon ile uyumlu ödem ve hipoekoik alan görülmüş. Ampirik amoksisilin tedavisi verilen hastanın mamografisinde BIRADS 3 lezyonlar görülmüş ve takibe alınmıştır.

Yazışma Adresi: Göksel Tanıgör

Ege Üniversitesi Tıp Fakültesi, Fiziksel Tıp ve Rehabilitasyon Anabilim Dalı

E-mail: gtanigor@windowslive.com
HRCT sonucu sağ akciğer üst lob paravertebral alanda $8 \times 4$ mm'lik plevra ile devam eden nodüller görülmüş, plevral kalınlaşma veya plak görünümü tariflenmiştir. Yapılan solunum fonksiyon testleri olağan sınırlarda saptanmıştır.

Dış merkez EMG'nin sonuç kısmına ulaşımıştır, akut süreçte miyopatiye işaret eden bulgular tariflenmiştir. Kas biyopsisi gerçekleştirilmemiş.

Dış merkez laboratuvarda ANA ve profili çalışılmıştır, ANA 1/320 benekli patern pozitif iken profil Anti Jo1 dahil negatif görülmüştür.

Başka bir merkezde alınan cilt biyopsisi sonucu "Düzenli epidermis, papiller dermiste, kapiller düzeyde damarlar çevresinde minimal şiddette mononükleer hücresel infiltrasyon" olarak yorumlanmış. Yatış sonunda CK değeri 2500 görülmüş olup, CRP başlangıçta $5,73 \mathrm{mg} / \mathrm{dl}$ iken 1,3 olarak saptanmış.

Hastada bu süreçte son birkaç haftada peroral $90 \mathrm{mg}$ metilprednizolon başlanmış.

Kliniğimizde gerçekleştirilen ilk muayenede tarif edilen lezyonlar, yüzde malar bölgeyi tutmayan eritem ve periungual eritem görülmüştür. Kas kuvvetleri proksimallerde üst ekstremitede sağda $2-3 / 5$, solda 3$4 / 5$, alt ekstremitede $2 / 5$ saptanmıştır, distal kas kuvveti kaybı minimal görülmüştür. Sol aksillada $2 \mathrm{~cm}$ mobil LAP saptanmıştır. 
Hastada mevcut bulgular ile tarafımızca da dermatomiyozit düşünülmüş, $1 \mathrm{mg} / \mathrm{kg}$ gün metilprednizolon (64 mg) ve $15 \mathrm{mg} / \mathrm{hafta}$ metotreksat başlandı. Bu süreçte proksimal kasları kuvvetlendirmeye yönelik yorgunluk sınırında ev egzersiz programı verildi.

Steroid tedavisine yanıt veren hastada klinik olarak şikâyetler azalmış ve inflamatuvar belirteçler gerilemiştir, bir yıllık takip sürecinde steroid dozu kademeli olarak azaltılmıştır.

Bir yıl sonra poliklinik kontrolünde sol supraklaviküler ve posterior servikal lenfadenopati (LAP) saptanan hasta, sağ kasıkta ağrı tariflemekte ve trendelenburg yürüyüşü yapmaktaydı. Tetkik için yatırıldı.

Hastanın yatış sırasında gerçekleştirilen tetiklerinde supraklaviküler bölgede en büyüğü $9,7 \times 9,3 \mathrm{~mm}$ boyutunda olan, bazılarının ekojen hilusu seçilemeyen hipoekoik lenf bezleri görülmüş olup, MRG sonucu kalçada en büyüğü sağ asetabulumda olmak üzere değişik bölgelerde kemik iliği infiltrasyonu veya fokal konfigürasyonda lezyonlar görüldü, pelvik MRG'de ise sklerotik ve litik özellikte kemik lezyonları saptandı (Şekil-1).

Onkolojiye danışılan hastada servikal LAP biyopsisi planlandı, öncesinde KBB tarafından boyun MRG istendi. Boyun MRG ile LAP'ların vasıfları tanımlandı ve biyopsi alındı.

Biyopsi sonucu "Histopatolojik incelemede lenf nodülüne ait herhangi bir morfolojik yapı izlenmemekte olup, yoğun vaskülarizasyon gösteren fibrotik bağ dokusu zemininde herhangi bir diferansiasyon bulgusu vermeyen malign epitelyal tümör infiltrasyonu saptanmıştır" olarak raporlandı.

Hastanın izlemleri devam etmektedir. Hastadan tıbbi verilerinin yayınlanabileceğine ilişkin yazılı onam belgesi alınmıştır.

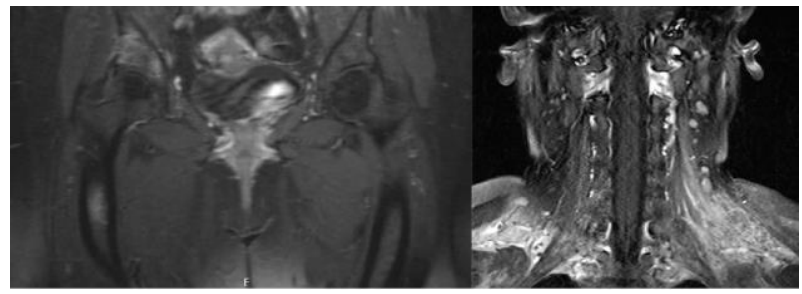

Şekil-1. Sağ asetabulum ve femur diyafizde kemik iliği infiltrasyonu şeklinde veya fokal konfigürasyonda lezyonlar, radyoloji tarafından belirtilen görüşte ön planda malignite düşünülmüştür. Sol supraklavikuler bölgede kortikal kalınlaşma gösteren lenf bezleri eşlik etmektedir.

\section{Tartışma}

Dermatomiyozit hastalarında malignite ile birliktelik bilinen bir durumdur. Diğer inflamatuvar miyozitlere göre dermatomiyozitte bu risk daha da artmış görülmektedir. Bu ilişki ile ilgili ilk yayınlar 1980'li yıllara dayanmaktadır (4). Tanıdan sonra geçen süre arttıkça bu risk azalmakla beraber beş seneye kadar bu artmış risk devam etmektedir (5).

Erkek cinsiyet, hastalığın ortaya çıkış yaşı, kas veya deride daha ağır tutulum, artmış eritrosit sedimantasyon hızı $(E S H)$ ve CRP değerleri, düşük albümin, miyozit antikorlarında negativite ve pozitif $155 / 140$ antikoru risk faktörleri arasındadır (6).

Bütün bunların yanında atipik ve yaygın deri tutulumları, kutanöz nekroz ve vaskülit, kas biyopsisinde kapiler hasar bulguları, akciğer tutulumu yokluğu ve immünosupresan kullanımı da miyozitlerde malignite açısından ilişkili görülmüş faktörlerdir (7).

Bu nedenle hastaların tanı anında maligniteler açısından taranması ve izlemleri boyunca da bulgular arasında kuşkulu olmak gerekmektedir.

\section{Kaynaklar}

1. Madan V, Chinoy H, Griffi ths CE, Cooper RG . Defining cancer risk in dermatomyositis. Part I. Clin Exp Dermatol 2009;34:451-55.

2. Callen JP. Dermatomyositis and malignancy. Clin Rheum Dis 1982;8:369-81.

3. Buchbinder R, Hill CL. Malignancy in patients with inflammatory myopathy. Curr Rheumatol Rep 2002;4:415-26.

4. Manchul LA, Jin A, Pritchard KI, et al. The frequency of malignant neoplasms in patients with polymyositis-dermatomyositis. A controlled study. Arch Intern Med 1985;145:1835-9

5. Buchbinder R, Forbes A, Hall S, Dennett X, Giles G. Incidence of malignant disease in biopsy-proven inflammatory myopathy. A population-based cohort study. Ann Intern Med 2001;134:1087-95.

6. Chinoy H, Cooper RG. Polymyositis and dermatomyositis. In: Watts RA, Conaghan PG, Denton C, Foster H, Isaacs J, MüllerLadner U (eds). Oxford textbook of rheumatology $4^{\text {th }}$ ed. United Kingdom. Oxford University Press; 2013:1009-21.

7. Ponyi A, Constantin T, Garami M, et al. Cancer-associated myositis: clinical features and prognostic signs. Ann N Y Acad Sci 2005;1051:64-71. 